\section{The giant venous wave: Lancisi's sign}

A 55-year-old female patient was admitted to our hospital with symptoms of progressive heart failure. Her history revealed mitral and aortic valve replacements and tricuspid annuloplasty for severe rheumatic mitral and aortic stenosis with severe tricuspid regurgitation 20 years ago. She also had diabetes mellitus and persistent atrial fibrillation (AF). Physical examination was notable for crackles in both lungs, elevated jugular venous pressure, hepatomegaly, severe lower-extremity edema and ascites. A grade 3/6 holosystolic murmur that was augmented with inspiration was noted at the left lower sternal border. Examination of the neck revealed a palpable, polymorphic venous pulsation, which represented giant C-V waves, known as Lancisi's sign (Video 1). Electrocardiography revealed an AF rhythm. Chest radiography showed massive cardiomegaly with a cardiothoracic ratio of 0.8 . Transthoracic echocardiography revealed functioning prosthetic

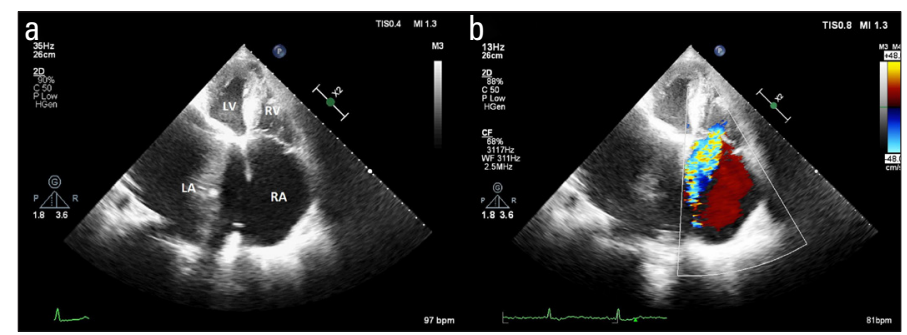

Figure 1. Transthoracic echocardiography showing (a), severe biatrial dilation and (b) severe tricuspid regurgitation

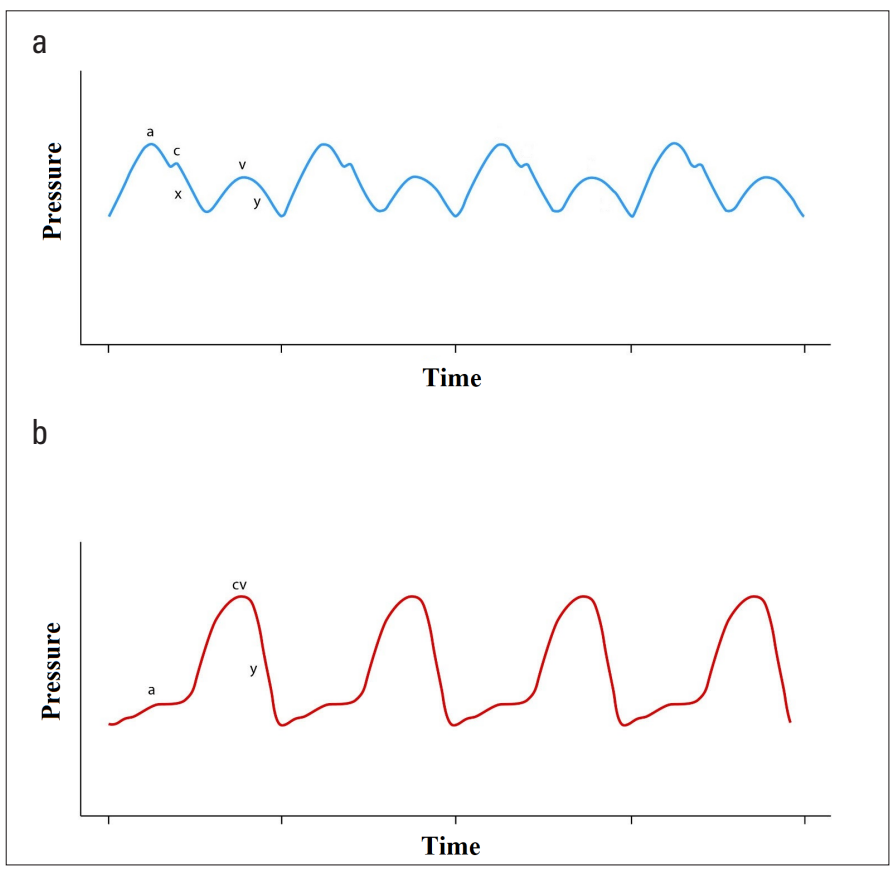

Figure 2. (a) Schematic normal jugular venous pressure waves and; (b) right atrial pressure tracing (schematic) of patients with giant $\mathrm{C}-\mathrm{V}$ waves mitral and aortic valves, severe paravalvular mitral regurgitation, normal left ventricular systolic function with an EF of $60 \%$, severe biatrial dilation and severe tricuspid regurgitation (TR) (Fig. 1, Video 2). Enlarged (51 mm) right ventricle, dilated $(32 \mathrm{~mm})$ and noncollapsing inferior vena cava and elevated $(76 \mathrm{~mm} \mathrm{Hg}$ ) pulmonary artery systolic pressure were also noted. She refused to receive any treatment for the paravalvular leak and was treated with intravenous furosemide with clinical improvement.

Lancisi's sign is a physical finding of severe TR which was first described by the Italian physician Giovanni Maria Lancisi (1). In the context of severe TR, during ventricular systole retrograde blood flow into the right atrium results in loss of the $x$ descent, creating a fused CV wave (Fig. 2) that appears as a large pulsation within the internal jugular vein which is often palpable. This wave is typically followed by an augmented y descent, which is the consequence of an increased pressure gradient between the right atrium and right ventricle (2). Lancisi's sign is not specific for the presence of severe TR and it might be false positive in patients with hyperdynamic state (3). This case demonstrates the importance of a careful physical examination of the jugular venous pulse in patients with symptoms of heart failure.

Informed consent: Written informed consent was obtained from the patient.

Video 1. Examination of the neck showing a palpable, polymorphic venous pulsation, which represents giant $\mathrm{C}-\mathrm{V}$ waves, known as Lancisi's sign

Video 2. Transthoracic echocardiography showing severe biatrial dilation and severe tricuspid regurgitation

\section{References}

1. Kato K, Nishizawa T, Goto M, Uematsu H. Lancisi sign: prominent C-V waves of severe tricuspid regurgitation. BMJ Case Rep 2021; 14: e243423. [Crossref]

2. Mansoor AM, Mansoor SE. Images in Clinical Medicine. Lancisi's Sign. N Engl J Med 2016; 374: e2. [Crossref]

3. Cha SD, Gooch AS. Diagnosis of tricuspid regurgitation. Current status. Arch Intern Med 1983; 143: 1763-8. [Crossref]

\section{Yalçın Velibey (D), Gökçem Ayan (D), Mesut Karataş (D), Erkan Kahraman (iD, Emre Can Parsova (iD, Özge Güzelburç (D) \\ Department of Cardiology, Siyami Ersek Thoracic and Cardiovascular Surgery Center, Training and Research Hospital; İstanbul-Turkey}

Address for Correspondence: Dr. Yalçın Velibey,

Dr. Siyami Ersek Göğüs Kalp ve Damar Cerrahisi Eğitim ve Araştırma Hastanesi, Kardiyoloji Kliniği, İstanbul-Türkiye

Phone: +90 2164445257

E-mail: dr_yalchin_dr@yahoo.com.tr

(C) Copyright 2021 by Turkish Society of Cardiology -

Available online at

www.anatoljcardiol.com

DOI:10.5152/AnatolJCardiol.2021.526 